\title{
Analysis of Risk Factors for Deep Venous Thrombosis in Patients With Achilles Tendon Rupture: A Retrospective Study of 247 Patients
}

\section{Feiyu Cai}

First Affiliated Hospital of Xinjiang Medical University

Kai Liu

First Affiliated Hospital of Xinjiang Medical University

Yanshi Liu

First Affiliated Hospital of Xinjiang Medical University

Jiasharete Jielile

First Affiliated Hospital of Xinjiang Medical University

Aihemaitijiang Yusufu ( $\nabla$ ahmatjang@163.com )

First Affiliated Hospital of Xinjiang Medical University

\section{Research Article}

Keywords: Deep vein thrombosis, Achilles tendon rupture, Functional outcome, Risk factor

Posted Date: April 13th, 2021

DOl: https://doi.org/10.21203/rs.3.rs-404041/v1

License: (a) (i) This work is licensed under a Creative Commons Attribution 4.0 International License. Read Full License 


\section{Abstract \\ Background and purpose}

The high incidence of deep venous thrombosis (DVT) was presented in patients with Achilles tendon rupture (ATR), and affects the prognosis of patients significantly. The purpose of this study was to identify and quantify the risk factors for perioperative DVT and the role of DVT in clinical outcomes, which may provide a guideline for DVT prevention and Achilles tendon repair.

\section{Methods}

The study was conducted on 247 patients who underwent surgical treatment for ATR at our institution from 2009 to 2019. Ultrasound results from injury to 4 weeks after operation were collected to diagnose DVT. Odds ratios (OR) were calculated using logistic regression to describe factors associated with DVT diagnosis including sex, age, body mass index (BMI), nicotine usage, mechanism of injury, rupture side, types of rupture, medical morbidity (hypertension, diabetes, coronary heart disease, stroke), time to operation, operative time and blood loss. The outcomes were assessed using the Achilles tendon Total Rupture Score (ATRS) and American Orthopaedic Foot and Ankle Society (AOFAS) Ankle Hind-Foot Scale Score at postoperative 3,6 , and 12 months.

\section{Results}

There were 216 males and 31 females with a mean age of 37.4 years (range from 20 to 75 years). Out of 247 patients, 113 patients were diagnosed with DVT during the perioperative period, accounting for $46 \%$ of total patients. The independent risk factors were identified with age $>40$ years (OR $0.41 ; 95 \% \mathrm{Cl} 0.21-$ $0.82 ; p=0.013), \mathrm{BMI}>26$ (OR 0.39; $95 \% \mathrm{Cl} 0.19-0.79 ; p=0.009)$, traumatic ATR (OR $2.44 ; 95 \% \mathrm{Cl} 1.22-$ 4.91; $p=0.012$ ), operative time (OR $0.95 ; 95 \% \mathrm{Cl} 0.91-1.01 ; p=0.028)$, and blood loss (OR $1.09 ; 95 \% \mathrm{Cl}$ $1.03-1.14 ; p=0.001$ ). Worse patient-subjective and functional outcomes were presented in patients with a perioperative DVT according to ATRS and AOFAS.

\section{Conclusions}

Routine thromboprophylaxis should be encouraged in patients with ATR requiring surgery, which was caused by trauma. Age $>40$ years and $\mathrm{BMI}>26$ were important risk factors for perioperative DVT. This study also showed that the presence of DVT of patients with ATR in the perioperative period has clear impairment of outcome within one year after surgery, which may postpone the return of athletes to the field severely.

\section{Background}


Deep venous thrombosis (DVT) of the lower extremities is a common complication in patients with Achilles tendon rupture (ATR). Aside from the fatal risk of DVTs causing a pulmonary embolism (PE), long-term morbidity of impaired subjective outcome may be caused considerably by symptoms such as chronic pain, secondary varicose veins, and ulcers [1]. Many previous studies have demonstrated that the highest risk of DVT associated with ATR was 35-50\% approximately, irrespective of surgical or nonsurgical treatment [2-4]. Despite chemoprophylaxis with low molecular weight heparin (LMWH) effectively prevents venous thromboembolism (VTE) in lower extremity trauma, an unsatisfactory effect was demonstrated on patients with ATR [5]. The same result was also been reported by Calder JDF et al. and considered that the insufficient blood circulation caused by the retraction of the ruptured tendon and immobilization of the limb may be the main reason for the high incidence of DVT and the poor preventive effect of LMWH [2].

Plenty of researches have been identified that increasing the venous return of lower limbs in patients with ATR prevents the occurrence of DVT effectively. Craik JD et al. demonstrated that the venous return of injured limb can be increased in patients with a partial or full weight-bearing compared to non-weightbearing [6]. Besides, active ankle and toe range of motion was also an effective method to prevent vascular stasis during the postoperative exercises [7, 8]. Furthermore, a randomized controlled trial conducted by Aufwerber $S$ et al. Illustrated that the risk of DVT could be minimized by an early exercise with more than $50 \%$ of body weight [9].

Although weight-bearing and active ankle motion as an effective method to prevent the occurrence of DVT during the period of leg immobilization have been confirmed, there are rare researches on the risk factors of perioperative DVT in patients with ATR. Therefore, the purpose of this retrospective study was to review the incidence and risk factors of perioperative DVT in patients who underwent surgical treatment to repair the Achilles tendon via the collection of the basic demographics, inter-operative data, and written questionnaires, which may guide the prevention of DVT after ATR, and the repair of the Achilles tendon.

\section{Patients And Methods}

\section{Patients}

This study was a retrospective assessment of 247 patients treated by the same surgery team for ATR between 2009, and 2019. The inclusion criteria in the studies were as follows: patients with an age between 16 and 75 years, acute ATR treated by minimally invasive approach, availability of ultrasonography results. Other patients with chronic ATR (acute ATR with delayed treatment more than 4 weeks), open ATR, current anticoagulation treatment, known kidney failure, heart failure with pitting edema, thrombophlebitis, a thromboembolic event during the previous 3 months, known malignancy, known hemophilia or thrombophilia, pregnancy, other severe trauma, and poor compliance to follow-up were excluded. Finally, 216 males and 31 females were assessed in this study according to inclusion criteria with a mean age of 37 years (range 20-75 years). The study was conducted following the 
Declaration of Helsinki, approved by our hospital institutional review board. The analyzed medical and ultrasonic data came from hospital records.

\section{Surgical procedure}

The operation was performed with the patient kept under spinal anesthesia. During the operation, two separate longitudinal incisions were made with $3-4 \mathrm{~cm}$ distance from the rupture site [10]. Careful dissection and complete release of tissue adhesions around the Achilles tendon, and the osteophytes with calcaneal tubercle hyperplasia were removed. In the extreme plantarflexion of the ankle joint, the1-0 PDS-II suture material (Ethicon, Somerville, NJ) can be used as the traction line twice, respectively, through the distal incision of the Achilles tendon, and continuous traction for more than ten minutes. From the distal incision, 3-6 longitudinal holes, approximate $2.0 \mathrm{~cm}$ deep, were drilled in the calcaneus within the calcaneal insertion using a $2.5 \mathrm{~mm}$ (in diameter) Kirschner wire to ensure the regenerated tendon attached to the bone firmly. After that, a transverse percutaneous calcaneal bone tunnel was drilled with a $3.0 \mathrm{~mm}$ (in diameter) Kirschner wire to prepare for percutaneous "Yurt bone" suturing [11, 12]. The plantar tendon was considered to be the most ideal biological suture graft material for strengthening the repair of the Achilles tendon. And the plantar tendon was used to bridge the ends of the distal and proximal Achilles tendon stump which plays a dual role in tendon transplantation and bridging suture.

\section{Postoperative management}

Following surgery, all patients were encouraged to do early postoperative rehabilitation without any fixation [10]. These patients were advised to lie prone or lateral on the bed without fixation or orthosis and with the knee at $\sim 60^{\circ}$ flexion and the ankle joint at $\sim 45^{\circ}$ plantar flexion. In addition, patients were instructed for the early active motion of the ankle and knee joints by a detailed physical rehabilitation regimen from postoperative day 1 . In this program, the increasing intensity of motion exercises was initiated at postoperative day 10 , followed by another increasing at week 3 . Full weight-bearing exercise, standing on the toes, and squatting were initiated at postoperative week 4 [13]. It should be noted that the exercise of tiptoe stepping on the operated side of the tendon on the balance $3 \sim 9 \mathrm{~kg}$ from postoperative day 3 was a novel component of the present program, which was greatly useful not only for reducing the patient's fear of early motion of the ankle joint but also for the surgeon to determine the time of walking with weight-bearing exercises according to the increase in tiptoe stepping.

\section{Data collection}

At admission, 2 and 4 weeks postoperatively, all patients were screened for DVT in the injured leg using unilateral compression duplex ultrasound (CDU). The basic demographics data were obtained by standardized self-administrated questionnaires at the beginning of in-patient treatment and complemented by extracting relevant data from hospital records, included: age, sex, body mass index $\left(\mathrm{BMI}=\right.$ weight $(\mathrm{kg}) /$ height $\left(\mathrm{m}^{2}\right)$ ), nicotine usage (continuous smoking for more than 3 months), rupture side (left or right), mechanism of injury (sports injury or trauma), types of rupture (total or partial), 
medical morbidity (hypertension, diabetes, coronary heart disease, and stroke), time to surgery, operative time and blood loss in operation.

Patient-subjective and functional outcomes were assessed at 3, 6, and 12 months postoperatively by completing the questionnaires or telephone interview, and all patients were evaluated by the Achilles tendon Total Rupture Score (ATRS) and American Orthopaedic Foot and Ankle Society (AOFAS) Ankle Hind-Foot Scale Score.

\section{Potential risk factors}

Continuous variables included age, time from injury to operation, operative time, and blood loss in operation. And sex, body mass index (normal weight $=B M 1<26 \mathrm{~kg} / \mathrm{m}^{2}$, overweight $=\mathrm{BMl}>26 \mathrm{~kg} / \mathrm{m}^{2}$ ), nicotine usage, mechanism of injury (sports injury or trauma), rupture side (left or right), types of rupture (total or partial rupture), medical morbidity (hypertension, diabetes, coronary heart disease, and stroke) were attributed to the categorical variables.

\section{Statistical analysis}

Statistical analysis was performed using SPSS (Version 22.0; IBM). The measurement data were assessed for normal or non-normal distribution. Continuous variables were analyzed by independentsamples T-test and expressed as the mean and standard deviation. For the categorical data, the chisquare test was used, expressing as number. Statistically significant difference was set at $P<0.05$.

The variable with a P-value of 0.05 or less in the chi-square test or T-test was entered to in the multivariate logistic regression model the relationship between the explanatory variable and the DVT and control the potential confusion of any included variables. The difference was statistically significant $(P<0.05)$.

\section{Results}

In total, 247 patients with ATR were included in this study after applying the inclusion and exclusion criteria. Of these patients, no one died, refused, or did not participate in the follow-up. Out of 247 patients, 113 patients were diagnosed with DVT according to the results of CDU, accounting for $46 \%$ of total patients. For these patients with DVT, LMWH $(0.4 \mathrm{ml}$, once a day) was used to subcutaneously inject to prevent VTE. 5 patients were recommended using the inferior vena cava filter (IVCF) to prevent fatal PE according to the evaluation performed by vascular surgeons. In one year follow-up, the tendon re-rupture appeared in 16 cases, tendon infection was presented in 6 cases, and tendon exposure occurred in 1 case. Sixteen tendon re-ruptures were repaired by additional surgery. Six tendon infections were treated by debridement and oral antibiotic therapy. One tendon exposure was covered with a random pattern skin flap.

\section{Risk Factors For Dvt}


Comparison of the demographic data between the DVT group and non-DVT group revealed that there was on significant difference concerning the sex, rupture side, and medical morbidity (hypertension, diabetes, and stroke) (Table 1). In the univariate logistic regression analysis, the following were associated significantly with a higher incidence of perioperative DVT: age $>40$ years, BMI $>26$, traumatic ATR, total ATR, coronary heart disease, time to operation, blood loss, operative time, and postoperative immobilization (Table 2). Age > 40 years (OR $0.41 ; 95 \% \mathrm{Cl} 0.21-0.82 ; p=0.013), \mathrm{BMI}>26$ (OR 0.39; 95\% Cl 0.19-0.79; $p=0.009$ ), traumatic ATR (OR 2.44; $95 \% \mathrm{Cl} 1.22-4.91 ; p=0.012)$, operative time (OR 0.95; $95 \% \mathrm{Cl} 0.91-1.01 ; p=0.028$ ), and blood loss (OR 1.09; 95\% Cl 1.03-1.14; $p=0.001$ ) were the independent risk factors for perioperative DVT in the multivariate logistic regression analyses (Table 3 ). Of all patients, $63 \%$ of patients older than 40 years were diagnosed with DVT, $59 \%$ of patients overweight patients (BMI > $26 \mathrm{~kg} / \mathrm{m}^{2}$ ) exhibited a DVT and $54 \%$ of patients with traumatic ATR developed a DVT. Patients with more blood loss in operation ( $153.98 \mathrm{ml} \pm 39.65 \mathrm{ml}$ ) or more operative time (127.7 minutes \pm 38.46 minutes) were more likely to suffer DVT. 
Table 1

Baseline characteristics of patients

\begin{tabular}{|c|c|c|c|c|}
\hline & $\begin{array}{l}\text { All } \\
\text { interventions } \\
(n=247)\end{array}$ & $\begin{array}{l}\text { DVT } \\
(n=113)\end{array}$ & $\begin{array}{l}\text { No DVT } \\
(n=134)\end{array}$ & $\begin{array}{l}P \\
\text { value }\end{array}$ \\
\hline Sex (male, \%) & 216(87.5) & $99(40.1)$ & 117(47.4) & 0.944 \\
\hline Age, mean $( \pm S D)$ & $38.95(11.51)$ & $42.74(11.94)$ & $35.75(10.13)$ & $<0.001$ \\
\hline BMI (\%) & & & & 0.001 \\
\hline$>26$ & $100(40.49)$ & 59(23.89) & $41(16.6)$ & \\
\hline$<26$ & 147(59.51) & $54(21.86)$ & 93(37.65) & \\
\hline Nicotine usage (yes,\%) & 97(39.27) & $50(20.24)$ & 47(19.03) & 0.143 \\
\hline Mechanism of injury (\%) & & & & 0.017 \\
\hline Sports injury & 134(54.25) & $52(21.05)$ & 82(33.2) & \\
\hline Trauma & 113(45.75) & $61(24.7)$ & $52(21.05)$ & \\
\hline Rupture side (\%) & & & & 0.798 \\
\hline left & 166(67.21) & 75(30.36) & $91(36.84)$ & \\
\hline Right & $81(32.79)$ & 38(15.38) & $43(17.41)$ & \\
\hline Types of rupture (\%) & & & & 0.017 \\
\hline Total rupture & 176(71.26) & $89(36.03)$ & $87(35.22)$ & \\
\hline Partial rupture & $71(28.74)$ & $24(9.71)$ & 47(19.03) & \\
\hline \multicolumn{5}{|l|}{ Medical morbidity yes(\%) } \\
\hline Hypertension & $29(11.74)$ & 13(5.26) & $16(6.48)$ & 0.916 \\
\hline Diabetes & $22(8.91)$ & 8(3.24) & $14(5.67)$ & 0.356 \\
\hline Coronary heart disease & 26(10.53) & $17(6.88)$ & $9(3.64)$ & 0.034 \\
\hline Stroke & $14(5.67)$ & $7(2.83)$ & $7(2.83)$ & 0.743 \\
\hline $\begin{array}{l}\text { Time to operation (days), mean }( \pm \\
\text { SD) }\end{array}$ & $5.48(2.67)$ & $6.01(2.70)$ & $5.04(2.58)$ & 0.004 \\
\hline $\begin{array}{l}\text { Operative time (minutes), mean }( \pm \\
\text { SD) }\end{array}$ & $120.36(35.68)$ & 127.7(38.46) & 114.18(32.01) & 0.003 \\
\hline Blood loss $(\mathrm{ml})$, mean $( \pm \mathrm{SD})$ & 124.33(45.19) & 153.98(39.65) & 99.33(38.75) & $<0.001$ \\
\hline
\end{tabular}


Table 2

Univariate logistic regression analysis of risk factors for DVT

\begin{tabular}{|llll|}
\hline Variables & Odds ratio & Standard error & $P$-value \\
\hline Age $>40$ years & $2.92(1.68,5.07)$ & 0.282 & 0.001 \\
\hline BMI > 26 & $2.24(1.41,4.13)$ & 0.274 & 0.001 \\
\hline Traumatic injury (\%) & $0.58(0.34,0.99)$ & 0.271 & 0.044 \\
\hline Total rupture (\%) & $1.49(0.61,3.69)$ & 0.461 & 0.381 \\
\hline Coronary heart disease & $3.31(0.68,16.12)$ & 0.809 & 0.141 \\
\hline Time to operation (days) & $0.99(0.84,1.16)$ & 0.082 & 0.877 \\
\hline Operative time (minutes) & $1.06(1.01,1.11)$ & 0.026 & 0.039 \\
\hline Blood loss in operation (ml) & $0.92(0.88,0.97)$ & 0.026 & 0.001 \\
\hline Abbreviations: BMl, body mass index & & \\
\hline
\end{tabular}

\section{Table 3}

Multivariate logistic regression analysis of risk factors for DVT

\begin{tabular}{|llll|}
\hline Variables & Odds ratio & Standard error & $P$-value \\
\hline Age $>40$ years & $0.41(0.21,0.82)$ & 0.367 & 0.013 \\
\hline BMI > 26 & $0.39(0.19,0.79)$ & 0.362 & 0.009 \\
\hline Traumatic injury (\%) & $2.44(1.22,4.91)$ & 0.356 & 0.012 \\
\hline Operative time (minutes) & $0.95(0.91,1.01)$ & 0.025 & 0.028 \\
\hline Blood loss in operation (ml) & $1.09(1.03,1.14)$ & 0.026 & 0.001 \\
\hline Abbreviations: BMl, body mass index & & \\
\hline
\end{tabular}

\section{Outcomes}

In one year follow-up, exhibiting a DVT during the period of treatment was associated with a significantly lower ATRS at postoperative 3, 6, and 12 months (scoring 42.41, 66.40, and 82.81, respectively) than nonDVT (scoring 63.35, 78.31, and 91.46, respectively) $(p<0.001)$ (Fig. 1). Moreover, more symptoms in 1 year after surgery were detected in patients with a DVT compared to patients devoid of it.

According to AOFAS, patients suffering a DVT (scoring 48.19, 68,78 and 85.18, respectively) experienced the worse quality of life compared to patients without DVT (scoring 58.50, 77.72, and 91.71, respectively) at 3,6 , and 12 months after surgery $(P<0.001)$ (Fig. 2).

\section{Discussion}


Patients with Achilles tendon rupture (ATR) had the highest incidence to suffer deep venous thrombosis (DVT) compared to other common lower limb injuries, which may lead to various symptoms, even pulmonary embolism (PE) [13]. It has been confirmed by various studies that patients with leg immobilization were more likely to suffer from DVT, and early functional exercise after surgery was preferred to prevent the occurrence of DVT and promote early function recovery [14-17]. In this present study, many significant risk factors (age $>40$ years, BMI $>26$, traumatic ATR, total rupture, coronary heart disease, time to operation, blood loss, and operative time) were identified to contribute to the perioperative DVT which has a serious negative impact on the patient-subjective and functional outcomes. Age > 40 years (OR 0.41; 95\% Cl 0.21-0.82), BMI > 26 (OR 0.39; 95\% Cl 0.19-0.79), traumatic ATR (OR 2.44; 95\% Cl 1.22-4.91), operative time (OR 0.95; 95\% Cl 0.91-1.01), and blood loss (OR 1.09; 95\% Cl 1.03-1.14) were the independent risk factors for perioperative DVT in the multivariate logistic regression analyses.

The incidence of DVT in this study was 46\%, which is in good agreement with previous researches that demonstrated a 36-50\% DVT rate in patients with ATR irrespective of operation or conservative management $[18,19]$. Although aging (older than 40 years) is an independent risk factor for DVT, it is noteworthy that the incidence of DVT was $35.9 \%$ in young patients (< 40 years) in our cohort and this rate was much higher than other common lower limb injuries. [20-22]. This phenomenon may be related to the reductions in tendon stiffness and resistance to loads after the tendon rupture [23]. Additionally, the disappearance or weakening of the muscle pump may be another reason leading to the decrease of venous return in the lower extremity, then contributing to the occurrence of DVT.

An almost threefold increased odds for sustaining a DVT was found in overweight patients (BMI > $26 \mathrm{~kg} / \mathrm{m}^{2}$ ) in previous studies $[9,18]$. In the present study, a high incidence of perioperative DVT (about $59 \%$ ) was also presented in overweight patients $\left(\mathrm{BMI}>26 \mathrm{~kg} / \mathrm{m}^{2}\right)$. Obese patients may be at increased risk for DVT after ATR as a result of lower postoperative mobility, the ineffectiveness of mechanical prophylaxis, and elevated procoagulant inflammatory markers. There was a consensus that early full weight-bearing can not only prevent the occurrence of DVT, but also promote the early functional recovery of the ruptured tendon, and help athletes to return to the sports field earlier [9][24, 25]. Furthermore, a randomized controlled trial conducted by Susanna Aufwerber et al. demonstrated that a low amount of weight-bearing $\leq 50 \%$ in postoperative rehabilitation was an independent risk factor for DVT, and recommended that patients with the tendon surgery should be encouraged to load at least $50 \%$ of body weight in postoperative exercise [9]. However, in our observation, obese patients were more difficult to carry out the early full-weight exercise, which may be related to the increased cardiac load and the decreased exercise tolerance caused by obesity.

Sports injury is the main reason for ATR, and it occurs more frequently in young athletes, but it should be noted that the higher risk was associated with traumatic ATR (OR 2.44; 95\% Cl 1.22-4.91). Severe softtissue swelling and vascular damage caused by trauma may impede venous return in lower extremities, as well as decreased ankle motion due to local pain, resulting in venous blood flow stasis, which may promote the formation of thrombosis significantly. In our study, 61 patients with ATR caused by trauma 
exhibited a DVT in the perioperative period, accounting for $54 \%$ of patients with traumatic ATR. Furthermore, hypercoagulation state is another boosting thrombosis factor. Selby et al. and Meissner et al. demonstrated that the hypercoagulability state persists for a long time after trauma $[26,27]$. The hypercoagulability that follows serious trauma is likely multifactorial, resulting from excessive activation of coagulation, a reduction in coagulation inhibitors, and increased fibrinolytic inhibition [28-30].

Additionally, the operation itself is the introducing factor of the hypercoagulation state [31]. In the multivariate analysis, operative time (OR $0.95 ; 95 \% \mathrm{Cl} 0.91-1.01)$ and blood loss (OR $1.09 ; 95 \% \mathrm{Cl} 1.03-$ 1.14) both were the independent risk factors contributing to DVT. Patients with DVT exhibited more blood loss $(153.98 \mathrm{ml} \pm 39.65 \mathrm{ml})$ than patients who avoid DVT $(99.33 \mathrm{ml} \pm 38.75 \mathrm{ml})$. The same result has also been reported in other operations of the lower limb [22,32]. Moreover, the operative time may be increased by greater blood loss. In a previous study, a prolonged duration of operative time of more than 60 min increases the risk of thrombosis according to National Institute for Health and Clinical Excellence (NICE) [33].

The patient-subjective and functional outcomes were evaluated by ARTS and AOFAS at postoperative months 3,6 , and 12 in patients with and without DVT. The results demonstrated that patients who were not afflicted by a DVT exhibited better outcomes in one year after surgery. The poorer clinical outcomes in patients with DVT may be related to insufficiently postoperative exercise due to chronic pain and swelling in the lower extremity caused by DVT. Furthermore, older age and higher obesity have been confirmed to have a negative impact on Achilles tendon repair [34-38]. However, the effect of surgical and nonsurgical treatment on the outcome of ATR has been debated. In this study, we found that surgery-related factors such as trauma, blood loss, and operative time were independent risk factors for DVT and may further influence the outcome of ATR.

Yet, certain limitations existed in this study. Firstly, given its retrospective nature and small sample size, caution should be taken regarding the interpretation of our analytical results. In fact, the factors responsible for the occurrence of DVT are complex, and there may be more confounding factors in the analysis results. Secondly, insufficient postoperative management instruction could give rise to higher numbers of DVT. Thirdly, to get control of the limitations of our study, further studies with larger sample size, longer follow-up period, and multicenter design should be designed.

\section{Conclusions}

The study was performed for demonstrating the quantification of risk factors for DVT and their role allows one to determine the patient-subjective and functional outcomes, which is important for both clinicians and patients. Almost $46 \%$ of patients with ATR were diagnosed with DVT based on ultrasound findings. Age $>40$ years, BMI > 26, traumatic ATR, blood loss, and operative time were the independent risk factors. A routine thromboprophylaxis should be encouraged for patients with these risk factors to achieve better outcomes. 


\section{Abbreviations}

DVT

Deep venous thrombosis

ATR

Achilles tendon rupture

PE

Pulmonary embolism

LMWH

Low molecular weight heparin

BMI

Body mass index

CDU

Compression duplex ultrasound

IVCF

Inferior vena cava filter

ATRS

Achilles tendon rupture score

AOFAS

American Orthopaedic Foot and Ankle Society

NICE

National Institute for Health and Clinical Excellence

OR

Odds ratio

\section{Declarations}

\section{Ethics approval and consent to participate}

All methods in this retrospective study were carried out in accordance with the Declaration of Helsinki. This study was approved by the Ethics Committee of The First Aliated Hospital of Xinjiang Medical University. Written informed consent was obtained from all patients for their data to be recorded in our study.

\section{Consent for publication}

Informed consent was obtained from all patients for their data to be published in our study.

\section{Availability of data and materials}

The datasets generated during and analyzed during the current study are available from the corresponding author on reasonable request. 


\section{Competing interests}

The authors declare that they have no competing interests.

\section{Funding}

This study was funded by the grants from National Natural Science Foundation of China (No. 81560357). The funding body was involved in the collection, analysis, and interpretation of data by supporting with salary for the time needed. They were not involved in the design or writing the manuscript

\section{Authors' Contributions}

FYC: Conducted the study. Collected, analyzed, and interpreted the data. Wrote the manuscript.

$\mathrm{KL}$ : Designed the study. Interpreted the data. Edited the manuscript.

YSL: Planned the project. Interpreted the data.

JJ: Planned the project. Reviewed the manuscript.

AY: Planned the project. Reviewed the manuscript.

Final approval of the version to be submitted: FYC, KL, YSL, JJ, AY

\section{Acknowledgments}

Not applicable

\section{References}

1. Brill JB, Badiee J, Zander AL, Wallace JD, Lewis PR, Sise MJ, Bansal V, Shackford SR: The rate of deep vein thrombosis doubles in trauma patients with hypercoagulable thromboelastography. $J$ Trauma Acute Care Surg 2017, 83(3):413-419.

2. Calder JD, Freeman R, Domeij-Arverud E, van Dijk CN, Ackermann PW: Meta-analysis and suggested guidelines for prevention of venous thromboembolism (VTE) in foot and ankle surgery. Knee Surg Sports Traumatol Arthrosc 2016, 24(4):1409-1420.

3. Domeij-Arverud E, Labruto F, Latifı A, Nilsson G, Edman G, Ackermann PW: Intermittent pneumatic compression reduces the risk of deep vein thrombosis during post-operative lower limb immobilisation: a prospective randomised trial of acute ruptures of the Achilles tendon. BONE JOINT J 2015, 97-B(5):675-680.

4. Domeij-Arverud E, Latifi A, Labruto F, Nilsson G, Ackermann PW: Can foot compression under a plaster cast prevent deep-vein thrombosis during lower limb immobilisation?BONE JOINT J 2013, 95B(9):1227-1231. 
5. Lapidus LJ, Rosfors S, Ponzer S, Levander C, Elvin A, Larfars G, de Bri E: Prolonged thromboprophylaxis with dalteparin after surgical treatment of achilles tendon rupture: a randomized, placebo-controlled study. J ORTHOP TRAUMA 2007, 21(1):52-57.

6. Craik JD, Clark A, Hendry J, Sott AH, Hamilton PD: The effect of ankle joint immobilization on lower limb venous flow. FOOT ANKLE INT 2015, 36(1):18-23.

7. Hickey BA, Morgan A, Pugh N, Perera A: The effect of lower limb cast immobilization on calf muscle pump function: a simple strategy of exercises can maintain flow. FOOT ANKLE INT 2014, 35(5):429433.

8. Stein PD, Yaekoub AY, Ahsan ST, Matta F, Lala MM, Mirza B, Badshah A, Zamlut M, Malloy DJ, Denier JE: Ankle exercise and venous blood velocity. Thromb Haemost 2009, 101(6):1100-1103.

9. Aufwerber S, Heijne A, Edman G, Grävare Silbernagel K, Ackermann PW: Early mobilization does not reduce the risk of deep venous thrombosis after Achilles tendon rupture: a randomized controlled trial. Knee surgery, sports traumatology, arthroscopy : official journal of the ESSKA 2020, 28(1):312319.

10. Aisaiding A, Wang J, Maimaiti R, Jialihasi A, Aibek R, Qianman B, Shawutali N, Badelihan A, Bahetiya W, Kubai $A$ et al: A novel minimally invasive surgery combined with early exercise therapy promoting tendon regeneration in the treatment of spontaneous Achilles tendon rupture. INJURY 2018, 49(3):712-719.

11. Holm C, Kjaer M, Eliasson P: Achilles tendon rupture-treatment and complications: a systematic review. Scand J Med Sci Sports 2015, 25(1):e1-e10.

12. Jielile J, Bai JP, Sabirhazi G, Redat D, Yilihamu T, Xinlin B, Hu G, Tang B, Liang B, Sun Q: Factors influencing the tensile strength of repaired Achilles tendon: a biomechanical experiment study. Clin Biomech (Bristol, Avon) 2010, 25(8):789-795.

13. Jielile J, Badalihan A, Qianman B, Satewalede T, Wuerliebieke J, Kelamu M, Jialihasi A: Clinical outcome of exercise therapy and early post-operative rehabilitation for treatment of neglected Achilles tendon rupture: a randomized study. Knee Surg Sports Traumatol Arthrosc 2016, 24(7):21482155.

14. Domeij-Arverud E, Latifi A, Labruto F, Nilsson G, Ackermann PW: Can foot compression under a plaster cast prevent deep-vein thrombosis during lower limb immobilisation?BONE JOINT J 2013, 95B(9):1227-1231.

15. Healy $B$, Beasley R, Weatherall M: Venous thromboembolism following prolonged cast immobilisation for injury to the tendo Achillis. J Bone Joint Surg Br 2010, 92(5):646-650.

16. Kock HJ, Schmit-Neuerburg KP, Hanke J, Rudofsky G, Hirche H: Thromboprophylaxis with lowmolecular-weight heparin in outpatients with plaster-cast immobilisation of the leg. LANCET 1995, 346(8973):459-461.

17. Nilsson-Helander $\mathrm{K}$, Thurin A, Karlsson J, Eriksson BI: High incidence of deep venous thrombosis after Achilles tendon rupture: a prospective study. Knee Surg Sports Traumatol Arthrosc 2009, 17(10):1234-1238. 
18. Zee AA, van Lieshout $K$, van der Heide $M$, Janssen $L$, Janzing HM: Low molecular weight heparin for prevention of venous thromboembolism in patients with lower-limb immobilization. Cochrane Database Syst Rev 2017, 8:D6681.

19. Nilsson-Helander K, Thurin A, Karlsson J, Eriksson Bl: High incidence of deep venous thrombosis after Achilles tendon rupture: a prospective study. Knee Surg Sports Traumatol Arthrosc 2009, 17(10):1234-1238.

20. Arverud ED, Anundsson P, Hardell E, Barreng G, Edman G, Latifi A, Labruto F, Ackermann PW: Ageing, deep vein thrombosis and male gender predict poor outcome after acute Achilles tendon rupture. BONE JOINT J 2016, 98-B(12):1635-1641.

21. Park $\mathrm{YH}, \mathrm{Kim} \mathrm{TJ}$, Choi GW, Kim HJ: Age is a risk factor for contralateral tendon rupture in patients with acute Achilles tendon rupture. Knee Surg Sports Traumatol Arthrosc 2020, 28(5):1625-1630.

22. Fu YH, Liu P, Xu X, Wang PF, Shang K, Ke C, Fei C, Yang K, Zhang BF, Zhuang Y et al: Deep vein thrombosis in the lower extremities after femoral neck fracture: A retrospective observational study. $J$ Orthop Surg (Hong Kong) 2020, 28(1):615561460.

23. Magnusson SP, Narici MV, Maganaris $\mathrm{CN}$, Kjaer M: Human tendon behaviour and adaptation, in vivo. $J$ Physiol 2008, 586(1):71-81.

24. Aufwerber S, Heijne A, Edman G, Silbernagel KG, Ackermann PW: Does Early Functional Mobilization Affect Long-Term Outcomes After an Achilles Tendon Rupture? A Randomized Clinical Trial. Orthop J Sports Med 2020, 8(3):1811953946.

25. Lu J, Liang X, Ma Q: Early Functional Rehabilitation for Acute Achilles Tendon Ruptures: An Update Meta-Analysis of Randomized Controlled Trials. J FOOT ANKLE SURG 2019, 58(5):938-945.

26. Meissner MH, Chandler WL, Elliott JS: Venous thromboembolism in trauma: a local manifestation of systemic hypercoagulability?J Trauma 2003, 54(2):224-231.

27. Selby R, Geerts W, Ofosu FA, Craven S, Dewar L, Phillips A, Szalai JP: Hypercoagulability after trauma: hemostatic changes and relationship to venous thromboembolism. THROMB RES2009, 124(3):281-287.

28. Boldt J, Papsdorf M, Rothe A, Kumle B, Piper S: Changes of the hemostatic network in critically ill patients-is there a difference between sepsis, trauma, and neurosurgery patients? CRIT CARE MED 2000, 28(2):445-450.

29. Engelman DT, Gabram SG, Allen L, Ens GE, Jacobs LM: Hypercoagulability following multiple trauma. WORLD J SURG 1996, 20(1):5-10.

30. Meissner $\mathrm{MH}$, Chandler WL, Elliott JS: Venous thromboembolism in trauma: a local manifestation of systemic hypercoagulability?J Trauma 2003, 54(2):224-231.

31. Kupcinskiene K, Trepenaitis D, Petereit R, Kupcinskas J, Gudaityte R, Maleckas A, Macas A: Monitoring of Hypercoagulability by Thromboelastography in Bariatric Surgery. Med Sci Monit 2017, 23:1819-1826.

32. Zhang BF, Wei X, Huang H, Wang PF, Liu P, Qu SW, Li JH, Wang H, Cong YX, Zhuang Y et al: Deep vein thrombosis in bilateral lower extremities after hip fracture: a retrospective study of 463 patients. CLIN 
INTERV AGING 2018, 13:681-689.

33. Treasure T, Hill J: NICE guidance on reducing the risk of venous thromboembolism in patients admitted to hospital. J R Soc Med 2010, 103(6):210-212.

34. Barsoum MK, Heit JA, Ashrani AA, Leibson CL, Petterson TM, Bailey KR: Is progestin an independent risk factor for incident venous thromboembolism? A population-based case-control study. THROMB RES 2010, 126(5):373-378.

35. Fan L, Wu B, Wang HM, Yang H, Liu D, Zhang J, Wei D, Zhou M, Zhai ZG, Chen JY: [Incidence and influencing factors of venous thromboembolism after lung transplantation]. Zhonghua Yi Xue Za Zhi 2019, 99(24):1848-1852.

36. Chan MM, Hamza N, Ammori BJ: Duration of surgery independently influences risk of venous thromboembolism after laparoscopic bariatric surgery. SURG OBES RELAT DIS 2013, 9(1):88-93.

37. Kim JY, Khavanin N, Rambachan A, McCarthy RJ, Mlodinow AS, De Oliveria GJ, Stock MC, Gust MJ, Mahvi DM: Surgical duration and risk of venous thromboembolism. JAMA SURG 2015, 150(2):110117.

38. Olsson N, Petzold M, Brorsson A, Karlsson J, Eriksson BI, Silbernagel KG: Predictors of Clinical Outcome After Acute Achilles Tendon Ruptures. Am J Sports Med 2014, 42(6):1448-1455.

\section{Figures}

3 Months

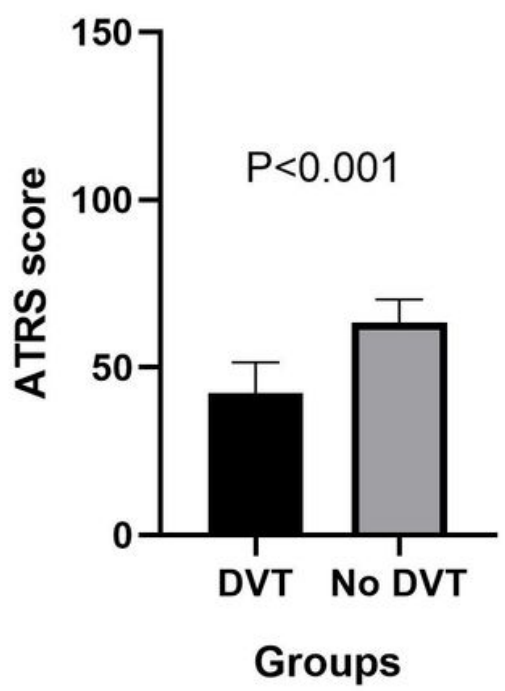

6 Months

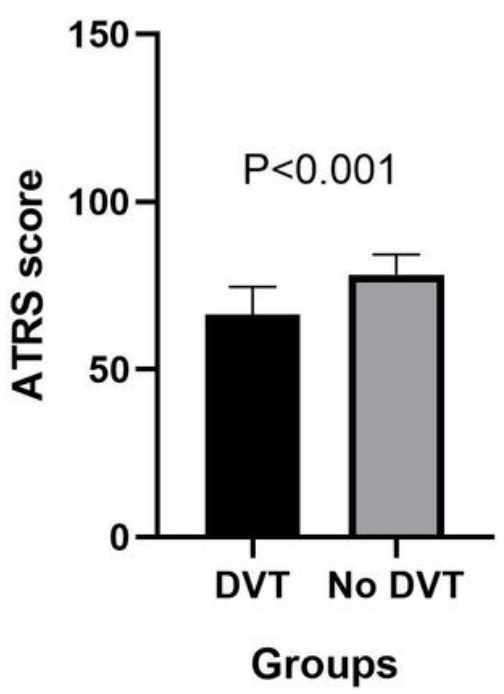

12 Months

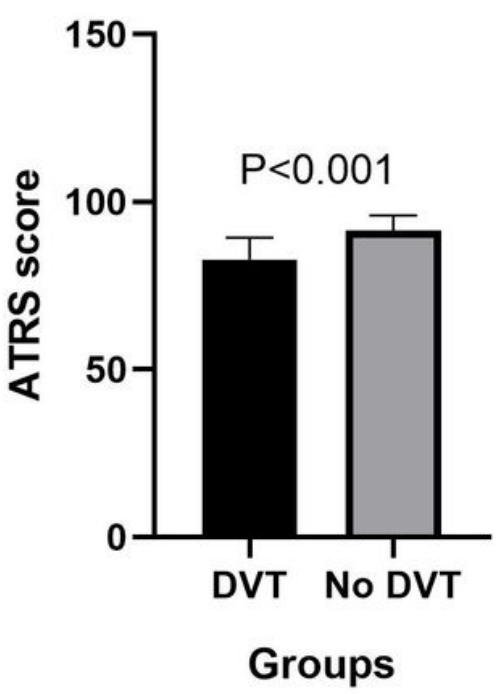

Figure 1

Comparison of the ATRS in the DVT group and non-DVT group. DVT, deep venous thrombosis; ATRS, The Achilles tendon Total Rupture Score. 
3 Months

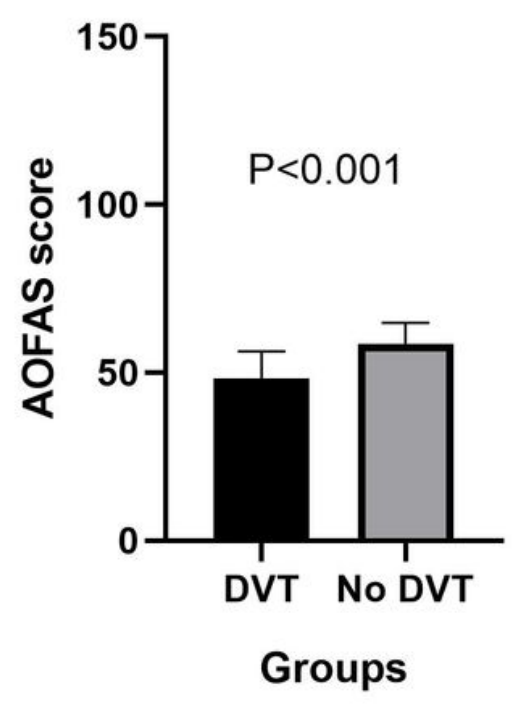

6 Months

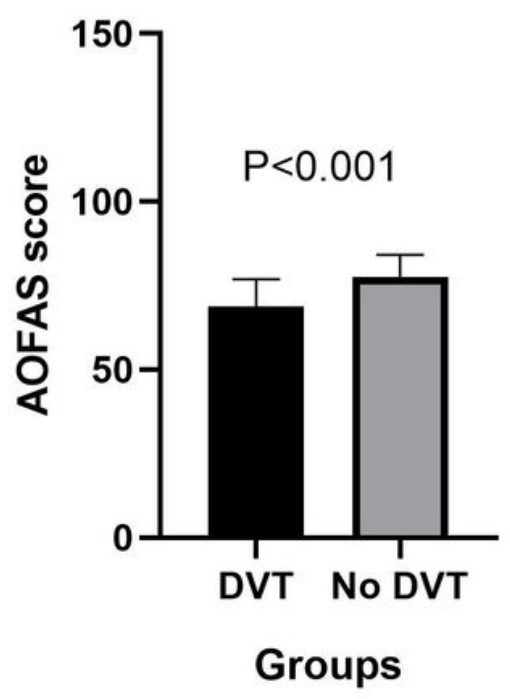

12 Months

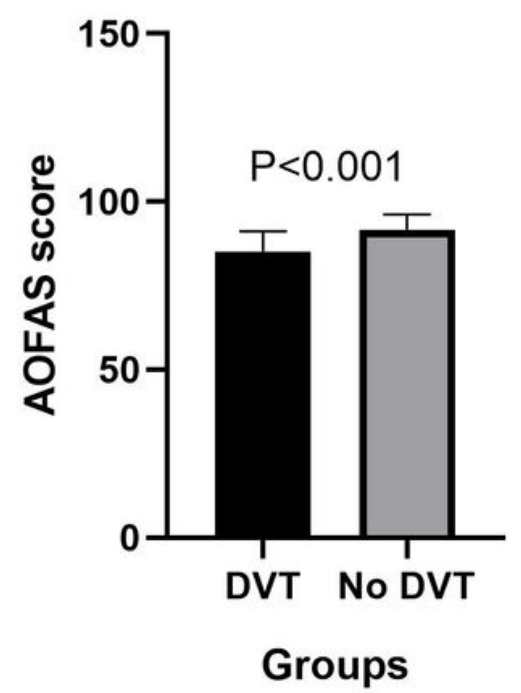

Figure 2

Comparison of the AOFAS in the DVT group and non-DVT group. DVT®deep venous thrombosis; AOFAS, American Orthopaedic Foot and Ankle Society (AOFAS) Ankle Hind-Foot Scale Score. 